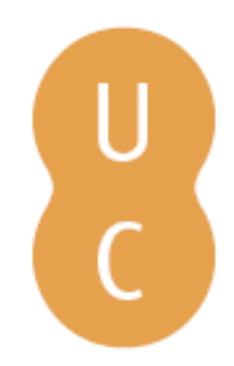

\title{
pommalina
}

\section{Pólos de cultura e criatividade em Lisboa: que papel na coesão da cidade?}

\author{
Autor(es): $\quad$ Carranca, Maria Adelaide \\ Publicado por: Imprensa da Universidade de Coimbra \\ URL \\ persistente: $\quad$ URI:http://hdl.handle.net/10316.2/30836 \\ DOI: $\quad$ DOI:http://dx.doi.org/10.14195/978-989-26-0244-8_49 \\ Accessed : $\quad$ 26-Apr-2023 16:06:40
}

A navegação consulta e descarregamento dos títulos inseridos nas Bibliotecas Digitais UC Digitalis, UC Pombalina e UC Impactum, pressupõem a aceitação plena e sem reservas dos Termos e Condições de Uso destas Bibliotecas Digitais, disponíveis em https://digitalis.uc.pt/pt-pt/termos.

Conforme exposto nos referidos Termos e Condições de Uso, o descarregamento de títulos de acesso restrito requer uma licença válida de autorização devendo o utilizador aceder ao(s) documento(s) a partir de um endereço de IP da instituição detentora da supramencionada licença.

Ao utilizador é apenas permitido o descarregamento para uso pessoal, pelo que o emprego do(s) título(s) descarregado(s) para outro fim, designadamente comercial, carece de autorização do respetivo autor ou editor da obra.

Na medida em que todas as obras da UC Digitalis se encontram protegidas pelo Código do Direito de Autor e Direitos Conexos e demais legislação aplicável, toda a cópia, parcial ou total, deste documento, nos casos em que é legalmente admitida, deverá conter ou fazer-se acompanhar por este aviso.

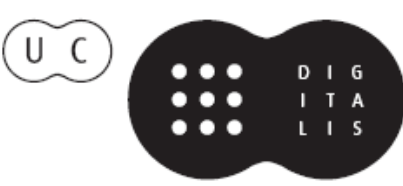




\section{TRUNFOS DE UMA}

\section{EOGRAFIA ACIVA}

\section{DESENVOLVIMENTO LOCAL,}

AMBIENTE,

ORDENAMENTO

E TECNOLOGIA

Norberto Santos

Lúcio Cunha

COORDENAÇÃO 
Maria Adelaide Carranca

e-Geo - Centro de Estudos de Geografia e Planeamento Regional

Faculdade de Ciências Sociais e Humanas, Universidade Nova de Lisboa

\section{PÓLOS DE CULTURA E CRIATIVIDADE EM LISBOA - QUE PAPEL NA COESÃO DA CIDADE? ${ }^{1}$}

\section{PROBlEMATIZAÇÃO - CULTURA E TERRITÓRIO: DA COMPETITIVIDADE À COESÃO}

Através do seu papel na criação de emprego qualificado, ligado a produtos e a processos inovadores, pela promoçáo de um ambiente de conhecimento e de estímulo intelectual, ou ainda através da organização de eventos, a cultura tem sido vista, no âmbito das políticas de desenvolvimento regional e urbano, sobretudo como uma forma de aumentar a competitividade e a atractividade dos lugares, como uma maneira de reforçar a sua visibilidade e atractividade, conferindo-lhes um "carácter global".

$\mathrm{Na}$ literatura sobre o tema, os autores têm concordado que "uma cidade competitiva não tem de ser criativa. No entanto, (...) a promoçáo de uma cidade criativa promove necessariamente a sua sustentabilidade e competitividade." (Costa et al., 2009: 2726)

Os impactes da cultura na coesão social têm sido também amplamente estudados e reconhecidos, sobretudo em contextos urbanos ligados a fenómenos de exclusão ou marginalidade, mas aqui trata-se quase sempre de intervençóes específicas (relacionadas sobretudo com o ensino e a promoção de artes performativas, como teatro, música, dança) e não pelo crescimento do "sector cultura" na sua globalidade.

Para lá da discussão sobre a relevância dos subsídios às actividades culturais, que tradicionalmente divide as visóes políticas de esquerda e de direita (Henriques, 2003), os indicadores parecem revelar que o contributo da cultura para o desenvolvimento das economias cresceu mais pela actuação da iniciativa associativa e privada do que pela intervenção do Estado (Gaspar, 2003).

O contexto de crise económica e financeira em que nos encontramos veio questionar as estratégias de desenvolvimento com forte pendor neoliberalista, assentes sobretudo nas preocupaçóes relacionadas com o aumento da competitividade, através de políticas muito orientadas para o crescimento da economia e do emprego, sobretudo do emprego qualificado nas áreas da ciência e da tecnologia, e pôs a descoberto as fragilidades deste modelo que lançou em processos de exclusão, mais ou menos acentuada, largas faixas de população mais frágeis e que mais têm sofrido os efeitos da crise.

\footnotetext{
${ }^{1}$ No âmbito do Projecto Territorial Cohesion in Portugal: new insights for spatial planning. Financiamento Plurianual FCT.
} 
No âmbito da União Europeia, os debates ${ }^{2}$ há pouco iniciados em torno do desenvolvimento nos próximos vinte anos indicam já alguns consensos: reforço da dimensão social, numa clara percepção de que é necessário revalorizar o modelo social europeu; promoção da actuação externa da UE, com o objectivo de que os valores europeus possam influenciar a actuação internacional; resposta aos grandes desafios que o mundo se enfrenta, globalização, energia e clima e alteraçóes demográficas.

Neste contexto, interessa reter o facto de o Estado ser novamente, e de forma inequívoca, chamado a desempenhar um papel mais interventivo, seja através do investimento público para dinamizar a economia e criar emprego, seja através do desenvolvimento de políticas sociais mais activas, seja através da sua capacidade de supervisão e de regulação dos mercados.

Num momento em que tudo parece portanto apelar a um "regresso" às medidas de reforço à coesão, no sentido de se conseguir um maior equilíbrio entre as dimensôes competitividade e social, importa questionarmo-nos em que medida poderá a cultura desempenhar também um papel na promoção da coesão?

Esta questão deverá colocar-se para a globalidade do sector ${ }^{3}$, compreendendo os equipamentos, as iniciativas institucionais, os eventos, as escolas de artes, etc, que marcam a feição cultural de Lisboa, mas no âmbito do presente artigo procurar-se-ão pistas de reflexão com base na análise de um conjunto de pólos de cultura e de criatividade em Lisboa e do seu contributo para o reforço da coesão económica, social e territorial da cidade. Em que medida podem estes espaços contribuir para modificar a imagem da cidade relativamente à cultura $\mathrm{e}$ à criatividade? Será o papel destes espaços mais importante para o reforço da competitividade ou da coesão?

Num segundo plano interessa também perceber as (eventuais) vantagens de uma articulação ou mesmo de uma intervenção pública mais activa sobre as iniciativas da sociedade civil no campo da cultura.

\section{MÉTODO E ANÁLISE - PÓLOS DE CRIATIVIDADE EM LISBOA}

As preocupaçóes com os conceitos de criatividade urbana, de cidade criativa, de meios criativos, de espaços criativos, de bairro criativo, de indústrias criativas, bem como a articulação entre criatividade e cultura, apesar de terem já sido muito desenvolvidos por vários autores (Costa et al., 2009), estão ainda pouco consensualizados. De igual forma a relação entre cultura, criatividade e desenvolvimento urbano e territorial tem sido muito debatida mas há ainda muito a aprofundar.

Sem querer diluir a importância da clarificação dos conceitos, essencial num quadro onde reina ainda muita incerteza, não vamos alongar-nos aqui sobre o quadro conceptual relativo ao que designamos por pólos de cultura e criatividade. Esclareça-se, contudo, que estamos a referir-nos a projectos recentes que surgiram em Lisboa, de iniciativa da sociedade civil, alguns de carácter empresarial mas mais frequentemente de natureza associa-

\footnotetext{
${ }^{2}$ Este debate está a decorrer simultaneamente em várias sedes: reapreciação do Orçamento Comunitário, futuro da Estratégia de Lisboa, Estratégia de Desenvolvimento Sustentável, Grupo de Reflexão Gonzalez.

${ }^{3} \mathrm{O}$ futuro da investigação avançará nesse sentido. Aos pólos agora referidos serão acrescentados outros de natureza semelhante, bem como iniciativas como a Experimenta Design, Santos Design District ou festivais.
} 
tiva, com dimensôes, conteúdos e objectivos diversos, cujo traço comum é o desenvolvimento, a promoção e divulgação de actividades criativas e/ou culturais.

Estes pólos funcionam como incubadoras de criatividade e espaços de experimentação para artistas jovens, fora dos circuitos do mercado, e que necessitam geralmente de apoio logístico na fase inicial de desenvolvimento das suas actividades, ainda que em casos mais raros ocorram também mostras de nomes já reputados (como João Pedro Vale, João Paulo Feliciano ou Rui Chafes, na Ermida de Belém).

Surgem por vezes em amplos espaços fabris abandonados, logo não qualificados, com acessibilidades deficientes mas que envolvem baixos custos, ou em edifícios desocupados, sendo frequentemente o espaço concedido através de um empréstimo por parte das autoridades públicas. Apesar de não procurarem uma localização específica, antes aproveitando as oportunidades surgidas, revelam padróes de localização relativamente específicos: ou em antigas áreas industriais em declínio, o que em Lisboa, é quase sempre sinónimo de proximidade do rio Tejo, seja na área envolvente de Alcântara, seja na parte oriental da cidade, como no Poço do Bispo; ou em antigos palácios, casas nobres ou edifícios pombalinos, numa localização de centro de cidade ou num contexto de bairro histórico.

Genericamente estes projectos englobam ateliers de artistas, espaços de formação em artes, áreas dedicadas à exposição, comercialização e espectáculos ao vivo, por vezes também livrarias, desenvolvem quase sempre uma vertente complementar de restauração e por vezes integram ou funcionam esporadicamente como bares/discotecas. Podem enquadrar várias formas de artes performativas: teatro, música, dança, circo, bem como de artes plásticas: pintura, escultura, design, arquitectura, joalharia.

Têm um período de actividade muito alargado no dia, potencializando o aproveitamento do espaço físico em diferentes horários. De dia funcionam como sedes de empresas, ateliers e oficinas de trabalho e de ensaio, à noite, para além dos espectáculos, surgem, por exemplo, as mostras de cinema, os debates e apresentaçóes de obras, as conferências, ... A programação é, portanto, muito variada tanto nos conteúdos, como nos horários.

Este universo está ainda pouco estudado o que nos afasta, para já, de uma pretensão de exaustividade. Sem prejuízo de outros projectos que virão a ser incluídos em fases posteriores da investigação, foram seleccionados para este artigo, de forma empírica, casos que pretendem ser exemplificativos. Parece-nos, contudo, ter englobado aqueles que têm maior visibilidade e maior expressáo em termos de eventos realizados e que, simultaneamente, permitem uma abrangência de situaçóes. A consulta sistemática ${ }^{4}$ do guia "Le Cool" e da revista "Time Out" para Lisboa, permitiu-nos, de alguma forma, validar esta selecção: Lx Factory, ZDB - Galeria Zé dos Bois, Travessa da Ermida, Fábrica do Braço de Prata, Crew Hassan, Bacalhoeiro, Carpe Diem Arte e Pesquisa.

Em síntese, nestes espaços vive-se um fervilhar de actividades relativamente informais, ou, se quisermos, alternativas face aos padrôes mais tradicionais das iniciativas e eventos culturais. Pretendem funcionar como pólos promotores e difusores de cultura e/ou de criatividade e como residências de artistas, promovendo uma programaçáo a baixos preços ou gratuita para públicos também eles alternativos, na medida em que procuram produtos além da norma.

\footnotetext{
${ }^{4}$ Com início em Março de 2009.
} 


\section{RESUltados - FutURO dOS PÓlOS DE CRIATIVIDADE: SOBREVIVÊNCIA OU SUCESSO? COESÃO OU RUPTURA?}

O que pretendemos discutir neste ponto é em que medida estes projectos poderão contribuir para o reforço da coesão urbana em Lisboa. Ou será, pelo contrário, que estas ilhas de cultura e criatividade se desenvolvem e pretendem manter-se como espaços de ruptura? Será essa característica fundamental à sua sobrevivência e sucesso?

Esta análise debruça-se sobre as três dimensôes da coesão: a social, a económica e a territorial.

No que se relaciona com os impactes sociais devemos questionarmo-nos se estes pólos funcionarão como locais de integração social e de tolerância, verdadeiramente abertos à diferença, ou se, pelo contrário, cultivam, por trás de uma imagem de aparente descontracção, um ambiente com códigos sociais específicos (vestuário, imagem, estilos de vida, valores estéticos, formas de expressão, ...) onde é difícil penetrar.

Inegável é que estes espaços desenvolvem um espírito identitário forte, que os distingue dos espaços mais tradicionais da cultura, e que, por vezes, os aproxima entre si, outras vezes os distancia, individualizando-os. Também inegável parece ser o facto destas estruturas terem criado os seus públicos e de que esses públicos se têm vindo a alargar, ainda que eventualmente trazendo uma nova segmentação de públicos.

Porém, tal não tem que ser perspectivado como um aspecto negativo nem não-coesivo, desde que não signifique um fechamento aos outros, nem uma atitude autista em torno das suas capacidades específicas. Pelo contrário, ao criarem novos públicos, novos hábitos e novos consumos culturais, introduzem elementos de urbanidade e valorizam o capital territorial da cidade. Não se constrói a integração social a partir da uniformização, nem apenas com vivências lado a lado mas que não se cruzam (EriCarts, 2008). O desenvolvimento social implica antes o relacionamento dos vários grupos, uma partilha na apropriação e utilização do mesmo espaço, da mesma cidade, do mesmo bairro, uma partilha de identidade que se constrói de forma diferente nestas diferentes escalas. Consoante a referência, isto é a escala, estamos mais próximos ou mais afastados de determinados grupos, de determinados interesses 5 . Os fenómenos de lacunas identitárias, por exemplo nas periferias das grandes cidades, conduzem à exclusão e à emergência de fracturas sociais, ao criar novas identidades os pólos criativos não segmentam, antes reforçam a coesão social.

Numa primeira aproximação a uma avaliação dos impactes sociais propóe-se que o público destes projectos seja caracterizado em relação ao seu local de residência, idade, escalão de rendimento, hábitos culturais e de lazer (incluindo férias), hábitos de consumo, habilitaçóes académicas, profissão e situação perante a profissão. Simultaneamente também a população residente na área envolvente deve ser inquirida sobre a sua percepção destes pólos e sobre as alteraçóes, positivas e negativas, que eles possam ter implicado, numa perspectiva funcional, de fluxos, de ambiente e paisagem urbanos, de novos visitantes, etc.

Quanto aos impactes económicos, assinale-se que numa fase inicial estes projectos se caracterizam por alguma fragilidade institucional que lhes confere um modo de funcionamento relativamente marginal face à economia formal. Esta marginalidade, apesar de facilitadora de

\footnotetext{
${ }^{5}$ O meu quintal em Lisboa está ao mesmo tempo em Lisboa, em Portugal e na Europa. O bom regionalismo é amá-lo por ele estar na Europa. Mas quando chego a este regionalismo, sou já português, e já não penso no meu quintal (Fernando Pessoa).
} 
um ambiente de criatividade, esconde por vezes a falta de qualificaçóes e o amadorismo que, a prazo, podem ser prejudiciais e insustentáveis de um ponto de vista económico.

À medida que vão ganhando dimensão, vai-se geralmente atenuando a informalidade institucional destes projectos. Há uma evolução organizacional e formal e a perda de flexibilidade é compensada pelos ganhos em capacidade de gestão.

Estes pólos funcionam como ninhos de empresas e de artistas que isoladamente não conseguiriam desenvolver um projecto e que neste contexto partilham um espaço, serviços e públicos.

Nesta medida os pólos criativos geram empregos, comercializam produtos, realizam espectáculos, fornecem serviços de restauração. O seu impacte, medido em termos do valor acrescentado quantitativo, pode não ser muito significativo, mas os seus efeitos económicos na criação de emprego e de rendimento e os seus efeitos societais na abertura de mentalidades e possibilidade de descobertas na cidade prolongar-se-ão muito para lá das quantificaçóes imediatas.

Para medir os impactes económicos sugere-se para princípio a utilização de indicadores directos como o número de postos de trabalho criados, rendimento gerado, o número de visitantes por mês e o número de novos visitantes por mês, a percentagem do público que é estudante, a percentagem do público com formação em artes, a localização de novas empresas ou ateliers, a longevidade das empresas instaladas, o grau de dependência do apoio público (em \% do orçamento), a quantificação de outros apoios públicos (instalação, logística), o número de parcerias (público/privado/associativo).

No que se relaciona com os impactes territoriais, estes pólos provocam alteraçôes notórias nas áreas onde se localizam: qualificam os edifícios, ainda que por vezes introduzam rupturas ao nível da imagem da cidade e da arquitectura; trazem dinamismo a áreas funcionalmente deprimidas; incutem vitalidade a áreas demograficamente envelhecidas; aumentam os fluxos de pessoas e de trânsito; animam e dão colorido aos bairros onde se inserem e tendencialmente pretendem e esforçam-se para se integrar nos tecidos urbanos pré-existentes.

Por outro lado, à semelhança do que se verifica nos bairros criativos, podem implicar processos de gentrificação ou de segregação socioeconómica ${ }^{6}$ e, por vezes, causam perturbação ou mesmo conflitos com os moradores, pelo tipo utilização do espaço público, horários, ruído.

Se olharmos para a escala da cidade, estes projectos que encerram geralmente especificidades muito próprias e que as promovem para se distinguirem, contribuem para a diversificação da imagem e das vivências urbanas. Ao contrário das áreas de comércio ou mesmo de alguns equipamentos culturais que têm contribuído para uma harmonização do espaço urbano em contextos geográficos muito diversos, e logo para uma harmonização das paisagens (e dos cheiros...) das cidades e para uma banalização dos modos de vida, os pólos criativos ao cultivarem a sua individualidade e os seus públicos, implicam antes uma diversificação e uma diferenciação dos espaços onde se localizam.

A avaliação dos impactes territoriais (positivos e negativos) é mais complexa, também porque menos imediata, que as anteriores e exige indicadores mais sofisticados. Sugere-se que seja feita uma abordagem a dois níveis, o da área envolvente próxima e o da cidade.

\footnotetext{
${ }^{6}$ Os bairros mais criativos são numa fase inicial do seu desenvolvimento relacionados com uma considerável variedade social e funcional, mas após algum tempo, afirmam-se como uma tendência gentrificadora ou de aumento de segregação socioeconómica. (Musterd 2006, citado por Costa et al., 2009).
} 
No primeiro podem ser utilizados aspectos como as alteraçôes funcionais na área envolvente (novas actividades económicas instaladas), alteraçôes aos horários do comércio e da restauraçáo da mesma área, eventual aumento da dificuldade de estacionamento, maiores fluxos de tráfego e pedonal, alteraçôes na utilização do espaço público, diminuição de fogos e edifícios devolutos. Quanto à cidade, importaria lançar um inquérito a uma amostra representativa sobre o conhecimento e a imagem que a população tem daqueles espaços, quanto à sua utilidade, quanto à qualidade e interesse da programação, quanto ao papel na animação da vida cultural da cidade em geral. Por fim, interessa entrevistar as autoridades públicas, quer as relacionadas com a gestão das cidades, quer as responsáveis pela cultura às escalas central, regional local sobre a eventual articulação da sua intervenção com estes pólos, sobre os impactes destes projectos e sobre os ensinamentos e boas práticas que daqui podem ser retirados.

\section{CONTRIBUTO PARA POLÍTICAS PÚBLICAS - ALGUMAS NOTAS FINAIS}

Nesta apreciação podemos concluir os projectos que designámos por pólos de criatividade têm um papel a desempenhar no desenvolvimento cultural e criativo da cidade: qualificam o território, reutilizam edifícios, introduzem dinâmicas funcionais em áreas em declínio.

De um ponto de vista económico, diversificam os públicos e criam emprego, promovem espectáculos e comercializam produtos.

Numa perspectiva social expandem actividades culturais e criativas a grupos que nem sempre se revêem na oferta cultural institucional, proporcionando-lhes o acesso a bens e serviços culturais.

Pelas características identificadas estes projectos podem ser fundamentais no atenuar de algumas tensões que a globalização trouxe às cidades:

- Ruptura VS continuidade (ou inovação VS património) - nos últimos anos as políticas públicas centraram-se no objectivo de inovar e de competir, relegando para segundo plano os aspectos da continuidade que são essenciais para valorizar a identidade dos lugares;

- Consumir a cidade VS produzir a cidade - a gestão da cidade deve preocupar-se com a urbanidade, com a valorização dos espaços, com a qualidade de vida e da paisagem e não apenas com a produção de áreas urbanas, muitas vezes sem "urbanidade";

- Cidade extraordinária VS a cidade ordinária - tal como a cidade, a cultura é não só erudita mas também comum, precisamos dela como dos outros serviços. Estes pólos contribuem para desmistificar os rituais da cultura, para não intimidar;

- Uma imagem para todas as cidades VS uma imagem para cada cidade, ou seja, a valorização das diferenças. Até quando vamos desejar a harmonização? Há um limite para querermos ser iguais? É necessário lutar contra a banalização e a "festivalização" dos espaços urbanos com vista a suscitar o prazer da descoberta;

- Direitos VS deveres - a cultura deve ser vista também como um meio de levar a criatividade e a inovaçáo a todos. O desenvolvimento cultural dos indivíduos aumenta a predisposição para a abertura ao outro; 
- Lealdade (ou pertença) VS tolerância (ou imigraçáo) - os migrantes estão a perder os seus mundos mas os locais também estão a perder os seus lugares. A visão actual de cosmopolitismo, muito assente num viajar "compulsivo", está a promover apenas os não-lugares, como os aeroportos e as estaçóes-de-serviço, mas não tem valorizado os espaços de sociabilidade dentro das cidades.

Os projectos descritos desenvolvem-se de forma bastante autónoma, mas os apoios públicos, em particular os relacionados com a cedência de instalaçôes, têm sido fundamentais. Uma maior articulação entre as autoridades públicas e os gestores destes projectos traria benefícios em geral e permitiria que estas boas práticas pudessem inspirar, por exemplo, a intervençáo pública em áreas onde tal não acontece tão espontaneamente. Por outro lado, e sem que isso significasse uma ingerência na programaçáo ou na sua organização interna, um elemento de cooperação que pode ser explorado seria a ligação a actividades dirigidas a grupos etários infanto-juvenis, construindo laços e pontes para uma educação e consciencialização para a cultura e a criatividade.

Também o apoio das políticas públicas à promoção de parcerias no âmbito destes agentes associativos entre si, entre os associativos e empresariais e entre os empresariais, facilitando um funcionamento em rede, a preparação de uma programaçáo conjunta, como ciclos de cinema, exposiçóes simultâneas do mesmo autor ou eventos temáticos, aliás com base em experiências de cooperação já realizadas com sucesso, seria outro ensinamento possível.

Sublinhe-se por fim o eventual interesse na criação de uma plataforma de agentes culturais com objectivos de cooperação, de troca de boas práticas e de apoio logístico de agentes culturais que permitiria criar massa crítica que desse outra dimensão aos projectos que têm funcionado isoladamente. Este efeito de escala poderia implicar, por sua vez, outros impactes na promoção da cidade no exterior. Uma plataforma desta natureza teve já um embrião em Lisboa, com base numa actuação individual e voluntarista de um grupo reduzido de agentes. A nosso ver a promoção de tal iniciativa pelas autoridades públicas permitiria potenciar resultados com evidentes benefícios para ambos os lados, sector público e privado, e sobretudo para os públicos da cidade de Lisboa.

\section{REFERÊNCIAS BIBLIOGÁFICAS}

Costa, Pedro; Seixas, João; Oliveira, Ana, (2009), Das Cidades Criativas à Criatividade Urbana? Espaço, Criatividade e Governança na Cidade Contemporânea, Actas do $1^{\circ}$ Congresso de Desenvolvimento Regional de Cabo Verde, $15^{\circ}$ Congresso da APDR - Cabo Verde, Redes e Desenvolvimento Regional, Cidade da Praia, Cabo Verde, 6 a 11 de Julho de 2009, www.apdr.pt/congresso/2009.

Culture Committee of Eurocities (2002), The Cultural Dimension of Urban Governance, Lille, policopiado.

Dinâmia/ISCTE/CML (2009), Estratégias para a Cultura em Lisboa, Câmara Municipal de Lisboa.

EriCarts (2008), Sharing Diversity National Approaches to Intercultural Dialogue in Europe, Comissão Europeia, ec.europa.eu/culture/key-documents.

Florida, Richard (2005), Cities and the Creative Class, New York, Routledge.

Gaspar, Jorge (2003), "Inserção da Área Metropolitana de Lisboa no País, na Península Ibérica e na Europa", in Tenedório, J. A. (dir) Atlas da Área Metropolitana de Lisboa, Lisboa, Ed. Área Metropolitana de Lisboa, pp. 29-43.

Henriques, Eduardo Brito (2003), Cultura e território, das politicas às intervençóes - Estudo geográfico do património histórico-arquitectónico e da sua salvaguarda, Dissertação para obtenção do grau de doutoramento apresentada à Universidade de Lisboa, policopiado. 
ICS/OAC (2005), Contribuiçôes para a formulaçâo de políticas públicas no horizonte 2013 relativas ao tema cultura, identidades e património, Relatório final, Estudos Preparatórios para o QREN www.qren.pt.

KEA (2009), Impact of culture on creativity, ec.europa.eu/culture/key-documents. 